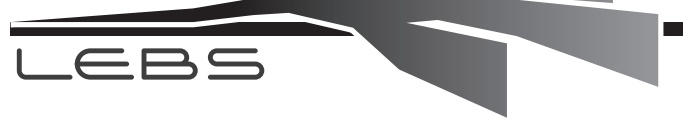

\section{A Mirror Has No Effect on Giving in the Dictator Game}

\author{
Yuki Niwa', Kai Hiraishi², Ryo Oda ${ }^{1,}$ \\ 1 Nagoya Institute of Technology, Nagoya 466-8555, Japan \\ 2 Kokoro Research Center, Kyoto University, Kyoto 606-8501, \\ Japan \\ *Author for correspondence (oda.ryo@nitech.ac.jp)
}

Evolutionary studies on human altruism toward strangers have proposed two motivations as proximate mechanisms for this behavior. The first involves the positive motivations inherent in expecting that actors will benefit in the long term by building a good reputation even if they accrue immediate costs for their altruistic behavior. The second involves the negative motivations inherent in avoiding identification as a norm violator. The presence of a mirror has been reported to enhance self-consciousness and evoke negative affect in response to an observer's eyes. We conducted the dictator game with and without a mirror. Participants were asked to complete a post-experiment questionnaire designed to investigate what they were thinking when they decided the amount of money to offer the recipient and to explore their perceptions of the experimental situation. Although the negative affect elicited by an observer's eyes was stronger under the mirror condition, the presence of the mirror did not increase the amount of money offered in the game.

\section{Keywords}

altruism, dictator game, mirror, reciprocity, thirdparty punishment

\section{Introduction}

People often demonstrate altruistic behaviors toward strangers with whom they have no committed relationship. From an evolutionary perspective, two motivations have been proposed as proximate mechanisms for this kind of altruism. The first is the positive motivation involved in the expectation that actors will benefit in the long term by "purchasing" increased cooperation from others when they "pay" through altruistic behavior. According to the indirect-reciprocity and competitive-altruism theories, information about an altruist's past behavior can be used by potential partners in making decisions about interactions even if an altruist is not directly rewarded by the actual recipient of the altruistic behavior (e.g., Wedekind \& Braithwaite, 2002). The second motivation involves the avoidance of being identified as a norm violator. According to the strong reciprocity model, humans have evolved, through group selection, to punish people who violate norms (Gintis, Bowles, Boyd, \& Fehr, 2003).

Altruistic behaviors toward strangers can be seen in experimental game situations such as the ultimatum, public goods, and dictator games (e.g., Guth, Schmittberger, \& Schwarze, 1982). Several studies have shown that individuals behaved more altruistically when subtle cues such as stylized eyes suggested that they were being watched (Burnham \& Hare, 2007; Haley \& Fessler, 2005; Rigdon, Ishii, Watabe, \& Kitayama, 2009). The same effect has been observed outside the laboratory (Bateson, Nettle, \& Roberts, 2006; Ernest-Jones, Nettle, \& Bateson, 2011). Oda, Niwa, Honma, and Hiraishi (2011) investigated the providers' motivation in the dictator game and showed that the "eye effect" was mediated by a positive motivation: participants expected that their actions would enhance their reputation in the eyes of a third party.

In the present study, we used a mirror instead of stylized eyes in the dictator game. Wiekens and Stapel (2008) reported that an observable mirror increased public and private self-awareness. Moreover, Diener and Wallbom (1976) compared the frequency of cheating in an anagram test under self-aware (seated in front of a mirror listening to one's own tape-recorded voice) and non-selfaware (seated to the side of the mirror listening to another's voice) conditions and reported that significantly more individuals cheated under the latter condition. These studies suggest that a mirror enhances self-consciousness and evokes negative affect in response to an observer's (in this case, one's own) eyes. If a negative motivation to avoid being identified as a norm violator led providers to allocate more money in the dictator game, a mirror would be expected to increase the amount of money allocated in this game.

\section{Methods}

\section{(a) Participants}

The sample consisted of 55 Japanese undergraduate students from Kyoto University (22 males and 33 females; mean age, $20.1 \pm 2.3$ ) who were recruited from a large pool of potential participants consisting of students from various departments on campus. Monetary rewards were provided as an incentive for participation.

\section{(b) Procedure}

We used a standard one-shot dictator game. Each 
provider was allocated $700 \mathrm{JPY}$ (about 8 USD) by the experimenter and was asked to share it with one other participant.

The participants entered a room individually and were informed of the rules of the dictator game by a first experimenter. They were asked to draw lots to determine whether they would be the provider or the recipient. The draw was manipulated to ensure that all subjects were providers. Participants were informed that the use of ID numbers throughout the experiment would ensure their anonymity and that only the second experimenter would know the decisions they reached. After receiving an ID number from the first experimenter, each participant was asked to enter an adjoining space that was separated by partitions and contained a desk and a chair. Each participant was assigned to either the mirror or the control condition. Under the mirror condition, a square-shaped standing mirror (30 $\mathrm{cm}$ wide $\times 150 \mathrm{~cm}$ high) was located diagonally in front of the desk. The mirror was reversed, and its back faced the participants under the control condition. After each participant waited alone for $1 \mathrm{~min}$, the first experimenter entered and passed the participant an envelope, an instruction sheet, and $700 \mathrm{JPY}$ (seven $100 \mathrm{JPY}$ coins) and then left immediately.

The instructions asked the participants to place the coins they wanted to share with the recipients into the envelope and to keep the rest for themselves. Then the participants left the space. Next, the second experimenter, who was waiting in the adjoining space, took the envelope and left. The first experimenter returned seconds later and asked the participants to complete a post-experiment questionnaire.

\section{(c) Post-experiment questionnaire}

The post-experiment questionnaire contained 17 items measuring the feelings or impressions of the participants during the dictator game. With the exception of several modified items, these were identical to those developed by Mifune, Hashimoto, and Yamagishi (2010) and employed by Oda et al. (2011). Participants indicated their level of agreement with each item using a 7-point Likert scale (Table 1). We also assessed the experimental manipulation by showing the participants six pictures and asking whether they had seen any of them in the separate space. They were asked to use a 4 -point Likert scale $(1=$ never seen, $4=$ strongly impressed) to rate the impression each had made. One of the six pictures showed the mirror we used.

\section{Results}

Twenty-eight participants (11 males and 17 females) were assigned to the control condition, and 27 (11 males and 16 females) were assigned to the mirror condition. Participants under the control condition allocated an average of $239.3 \pm 175.0 \mathrm{JPY}$ to the recipients, and participants under the mirror condition allocated an average of $248.1 \pm 112.2 \mathrm{JPY}$ to the recipients. Under the control condition, male participants distributed $245.5 \pm 187.6 \mathrm{JPY}$ and female participants gave $235.3 \pm 160.7$ JPY. Under the mirror condition, males allocated $227.3 \pm 128.6$ JPY and females gave 262.5 \pm 92.7 JPY. A two-way analysis of variance revealed that neither condition nor sex had a significant effect. The interaction of the two factors was also not significant. Participants under the mirror condition did not offer more money than did those under the control condition.

Following Oda et al. (2011), we conducted a principal-component analysis (PCA) on the17item post-experiment questionnaire. Five principal components with eigenvalues of more than 1 were extracted (Table 1). The cumulative explained variation of these five components was $72.5 \%$. Among the five components, only PC2 was significantly negatively correlated with the amount of money allocated to the recipients, $r=-.44, p<.01$. Other PCs were not significantly correlated with the amount of money allocated, $\mathrm{rs}=-.04-.22$. The

Table 1. Mean Score of Each Item and Loadings to Each Principal Component

\begin{tabular}{|c|c|c|c|c|c|c|c|}
\hline \multirow[b]{2}{*}{ Item } & \multirow[b]{2}{*}{$M$} & \multirow[b]{2}{*}{$S D$} & \multicolumn{5}{|c|}{ Principal component } \\
\hline & & & 1 & 2 & 3 & 4 & 5 \\
\hline \multicolumn{8}{|l|}{ I. How much did you think about the following points when you decided the amount you shared? } \\
\hline 1. Allocation of more money to the recipient benefits me as well as the recipient. & $2.6^{* *}$ & 1.6 & .346 & -.594 & .565 & .235 & -.116 \\
\hline 2. Someone is watching the amount of money I allocate to the recipient. & 3.7 & 2.0 & .668 & .380 & -.197 & .191 & .089 \\
\hline 3. I should give the amount the recipient expects. & $3.4^{*}$ & 1.7 & .523 & -.446 & -.394 & -.104 & -.134 \\
\hline 4. I only have to give as much money as I want to regardless of the recipient's desire. & 4.3 & 1.8 & -.507 & .630 & .176 & .155 & .156 \\
\hline 5. The recipient will be angry if I allocate more money to myself than to him or her. & 4.3 & 1.8 & .451 & -.202 & -.159 & -.525 & .316 \\
\hline 6. I should think of the recipient. & $4.5^{*}$ & 1.6 & .710 & -.300 & -.198 & -.006 & .315 \\
\hline 7. I will feel guilty if I don't share an equal amount with the recipient. & 3.8 & 1.9 & .407 & -.281 & -.174 & .293 & .592 \\
\hline 8. Allocation of less money to the recipient becomes disadvantageous for me as well as the recipient. & $3.0^{* *}$ & 1.9 & .434 & -.566 & .381 & .307 & .011 \\
\hline \multicolumn{8}{|l|}{ II. How concerned were you about the following points when you decided the amount you shared? } \\
\hline 1. Someone will see the amount of money I allocated and think I am a bad person. & 3.9 & 1.9 & 689 & .314 & -.469 & -.045 & .014 \\
\hline 2. I may run into the recipient after the experiment. & $2.3^{* *}$ & 1.8 & .683 & .145 & -.148 & .362 & -.301 \\
\hline 3. Someone will see the amount of money I allocated and think I am a good person. & $2.4^{* *}$ & 1.3 & .683 & .021 & -.344 & .232 & -.407 \\
\hline \multicolumn{8}{|l|}{ III. How did you perceive the experimental situation? } \\
\hline 1. A situation in which other people would find out how I behaved. & 3.3 & 1.7 & .710 & .248 & .397 & .003 & .162 \\
\hline 2. A situation in which other people would evaluate my behavior. & 4.0 & 2.1 & 619 & .340 & .246 & -.326 & .007 \\
\hline 3. A situation in which other people would see my behavior. & 3.5 & 1.9 & .690 & .418 & .345 & .041 & .206 \\
\hline 4. A situation in which other people would know if I did something bad. & $3.4^{*}$ & 1.8 & .758 & . 049 & .090 & .087 & -.034 \\
\hline 5. A situation in which I should be concerned that other people were watching me. & 4.2 & 2.0 & .664 & .383 & .254 & -.099 & -.189 \\
\hline 6. A situation in which my good behavior would be evaluated by someone. & $3.0^{* *}$ & 1.6 & .489 & -.262 & .203 & -.593 & -.244 \\
\hline Eigenvalue & & & 6.18 & 2.31 & 1.59 & 1.24 & 1.03 \\
\hline Explained variation (\%) & & & 36.3 & 13.6 & 9.3 & 7.3 & 6.0 \\
\hline
\end{tabular}


score for PC1 was significantly higher under the mirror $(0.42 \pm 0.93)$ than under the control $(-0.41 \pm$ 0.91 ) condition, $t(53)=3.35, \mathrm{p}<.01$, whereas scores for other PCs were not significantly different, $\mathrm{ts}=$ $-0.77-0.73$.

\section{Discussion}

This study showed that the presence of a mirror did not increase the amount of money offered in the dictator game. One possible reason for this finding is that the participants did not attend or react to the mirror we prepared. The post-experiment questionnaire, however, indicated that all the participants under the mirror condition rated the impression made by the mirror as 3 (considerably impressed) or 4 (strongly impressed), ruling out the interpretation that the participants experienced the mirror as insignificant.

Five PCs were extracted from the 17-item post-experiment questionnaire, but only PC2 was negatively correlated with the amount of money offered. The loadings suggested that PC2 was strongly related to the expectation of reciprocity because "Allocation of more money to the recipient benefits me as well as the recipient" and "Allocation of less money to the recipient becomes disadvantageous for me as well as the recipient" showed heavy loadings. Moreover, the loadings of both items were negative, indicating that the participants who expected reciprocity gave more money to the recipients. This result suggests that one motivation behind giving during the dictator game is an expectation of reciprocity. The score for $\mathrm{PC} 2$, however, was not significantly higher under the mirror condition, indicating that the mirror did not enhance the expectation of reciprocity.

On the other hand, the score for PC1 was higher under the mirror condition than under the control condition. The loadings suggested that PC1 was strongly related to fear of third-party punishment. For example, "A situation in which other people would find out how I behaved" and "A situation in which other people would know if I did something bad" showed heavy loadings. The PC1 score, however, was not correlated with the amount of money offered, indicating that negative affect in response to an observer's eyes did not influence the allocation of money. Oda et al. (2011) also reported that fear of third-party punishment did not affect giving during the dictator game. We could not compare these results directly because the current post-experiment questionnaire was somewhat different from that used by Oda et al. (2011). However, it is plausible that giving in the dictator game was not driven by negative motivations.

Heine, Takemoto, Moskalenko, Lasaleta, and Henrich (2008) indicated that North Americans located in front of a mirror were more self-critical and less likely to cheat than were those who were not located in front of a mirror. In contrast, the presence of a mirror had no impact on Japanese participants. They proposed that Japanese habitually engaged in self-awareness, rendering stimuli that enhanced this state ineffectual in this population. Our results with Japanese participants indicated that the negative affect elicited by an observer's eyes was stronger under the mirror condition, which did not support the results reported by Heine et al. (2008). However, our questionnaire and situation were not the same as those in the study conducted by Heine et al. (2008), which may have accounted for this difference. Moreover, Heine et al. (2008) found a marginally significant effect of the mirror on self-esteem among Japanese participants. It is possible that the different situation used in our study amplified this effect. Additional studies on relationships among PC1 scores, objective self-awareness, and cheating are needed. Cultural comparisons of our results would also be useful.

\section{Acknowledgements}

This study was supported by the Open Collaborative Research Project at the Kokoro Research Center, Kyoto University.

\section{References}

Bateson, M., Nettle, D., \& Roberts, G. (2006). Cues of being watched enhance cooperation in a real-world setting. Biology Letters, 2, 412-414. doi:10.1098/rsbl.2006.0509)

Burnham, T. C., \& Hare, B. (2007). Engineering human cooperation: Does involuntary neural activation increase public goods contributions? Human Nature, 18, 88-108. doi:10.1007/s12110007-9012-2

Diener, E., \& Wallbom, M. (1976). Effects of selfawareness on antinormative behavior. Journal of Research in Personality, 10, 107-111. doi:10.1016/0092-6566(76)90088-X

Ernest-Jones, M., Nettle, D., \& Bateson, M. (2011). Effects of eye images on everyday cooperative behavior: a field experiment. Evolution and Human Behavior, 32, 172-178. doi:10.1016 i.evolhumbehav.2010.10.006)

Gintis, H., Bowles, S., Boyd, R., \& Fehr, E. (2003). Explaining altruistic behavior in humans. Evolution and Human Behavior, 24, 153-172. doi:10.1016/S1090-5138(02)00157-5

Guth, W., Schmittberger, R., \& Schwarze, B. (1982) An experimental analysis of ultimatum bargaining. Journal of Economic Behavior and Organization, 3, 367-388. doi:10.1016/01672681(82)90011-7)

Haley, K. J., \& Fessler, D. M. T. (2005). Nobody's watching? Subtle cues affect generosity in an anonymous economic game. Evolution and Human Behavior, 26, 245-256. doi:10.1016 i.evolhumbehav.2005.01.002

Heine, S. J., Takemoto, T., Moskalenko, S., Lasaleta, J., \& Henrich, J. (2008). Mirrors in the head: Cultural variation in objective self-awareness. Personality and Social Psychology Bulletin, 34, 879-887. doi:10.1177/0146167208316921)

Mifune, N., Hashimito, H., \& Yamagishi, T. 
(2010). Altruism toward in-group members as a reputation mechanism. Evolution and Human Behavior, 31, 109-117. doi:10.1016 i.evolhumbehav.2009.09.004

Oda, R., Niwa, Y., Honma, A., \& Hiraishi, K. (2011). An eye-like painting enhances the expectation of a good reputation. Evolution and Human Behavior, 32, 166-171. doi:10.1016 i.evolhumbehav.2010.11.002

Rigdon, M., Ishii, K., Watabe, M., \& Kitayama, S. (2009). Minimal social cues in the dictator game. Journal of Economic Psychology, 30, 358367. doi:10.1016/i.joep.2009.02.002

Wedekind, C., \& Braithwaite, V. A. (2002). The long-term benefits of human generosity in indirect reciprocity. Current Biology, 12, 10121015. doi:10.1016/S0960-9822(02)00890-4

Wiekens, C. J., \& Stapel, D. A. (2008). The mirror and I: When private opinions are in conflict with public norms. Journal of Experimental Social Psychology, 44, 1160-1166. doi:10.1016 i.jesp.2008.02.005 